\title{
Unas de cal y muchas de "arena" en el sector público
}

\author{
Instituto de Derechos Humanos \\ de la Universidad Centroamericana "José Simeón Cañas"
}

Se debe garantizar a todas las personas una cabal realización de su condición ciudadana y, correspondientemente, su igualdad formal y material para asegurar la plena vigencia de los derechos económicos, sociales y culturales.

(Numeral 30 de la Declaración de Quito:

"Acerca de la exigibilidad y realización de los derechos económicos, sociales y culturales en América Latina y el Caribe", aprobada en julio de 1998.)

\section{Resumen}

"Hay incertidumbre sobre los progresos logrados en la institucionalidad para la defensa de los derechos humanos", "La exacerbación de la cultura de la violencia, la posesión de armas y los vacíos institucionales han expuesto a los salvadoreños a un alto riesgo de violencia física", etc. Estos juicios y otros fueron pronunciados por el Consejo Nacional para el Desarrollo Sostenible, en abril de este año. Este artículo expone la falta de respeto y de las libertades fundamentales a los que está sometida la población salvadoreña. Para ilustrar estos atropellos se citan, en esta ocasión, dos casos: el de la Dirección General de Correos y el de la Dirección General de Transporte Terrestre.

\section{Introducción}

Afirmar que en El Salvador la mayoría de la población está viviendo una situación difícil, es una manera bastante eufemística para referirse al estado en que se encuentran buena parte de las economías familiares, así como a sus condiciones mate- 
riales y, sobre todo, a los bajos niveles de esperanza de cientos de miles de personas que, hasta hace unos años, todavía soñaban con un país realmente distinto; un país dentro del cual, por fin, sus derechos y libertades fundamentales fuesen objeto de respeto. Pero las cosas no están como para abusar del optimismo que hasta ahora ha caracterizado a quienes se autodenominan "analistas políticos" de un "proceso" que, por más que intenten presentarlo de otra manera, dista mucho de ser un "modelo" por seguir.

Los siguientes son juicios lapidarios de un diagnóstico global que refuerza lo antes dicho: "Persisten grandes obstáculos que hacen el acceso al mercado sumamente inequitativo para muchos"; "El potencial de participar en el mercado de algunos salvadoreños se deteriora por sus condiciones de salud"; "La poca credibilidad en los partidos frena el involucramiento de la gente en los procesos políticos que afectan sus vidas"; "Una parte importante de niños, niñas y jóvenes se encuentran excluidos en la sociedad"; "Muchos salvadoreños enfrentan elevados riesgos de enfermar y morir por causas cuyo tratamiento se ha conocido por años"; "El patrón de crecimiento de los noventa no ha sido el más sensible para la creación de empleo".

Y continúan las partes de ese diagnóstico con lo siguiente: "Las carencias en las viviendas de los pobres caracterizan su inseguridad frente a las enfermedades y a la naturaleza"; "La contaminación del agua expone a los salvadoreños a alto riesgo de daños a su salud y la baja capacidad de regulación del agua superficial a alto riesgo de desastres naturales"; "La exacerbación de la cultura de la violencia, la posesión de armas y los vacíos institucionales han expuesto a los salvadoreños a un alto riesgo de violencia física"; "Hay incertidumbre sobre los progresos logrados en la institucionalidad para la defensa de los derechos humanos". La fuente de esas apreciaciones no es otra más que el documento titulado "El Salvador. Estado de la Nación en desarrollo humano 1999", publicado en abril del año en curso y cuya autoría corresponde al ente oficial conocido como Consejo Nacional para el Desarrollo Sostenible.

En ese mismo documento, al prologarlo, Bruno Moro' citó a James Wolfensohn — presidente del
Banco Mundial- cuando en octubre de 1998 se expresó ante su Junta de Directores de la siguiente manera: "Observamos que en la economía globalizada de nuestros días los países pueden avanzar hacia la economía de mercado, pueden privatizar, pueden acabar con los monopolios,... pueden atraer capital privado... y pueden reducir las subvenciones estatales, pero si no combaten la corrupción y adoptan prácticas razonables de gobiemo, si no introducen sistemas de protección social, si no logran el consenso social y político en tomo a la reforma, si no consiguen el apoyo de la población... si marginan a los pobres, si marginan a las mujeres y a las minorías indígenas, si no adoptan políticas de inclusión, su desarrollo corre peligro y no durará". Esa advertencia, viniendo de quien viene, debería ser escuchada con interés y atendida con diligencia por quienes ahora se encuentran en el poder político y económico dentro de nuestro país; sobre todo cuando el partido que por tercer período seguido se mantiene al frente del Ejecutivo ya comienza a pagar el costo político del proyecto que le está imponiendo a nuestra gente, pese a no haber enfrentado una fómula competitiva durante las pasadas elecciones. Sin embargo, de forma bastante triunfalista e irresponsable, estas personas y esos grupos se han dedicado a presumir en el exterior con los indicadores macros que todavía arroja El Salvador en esta hora. ¿Cuánto les durará el estado de cosas que aún les enorgullece?, no lo sabemos. El caso es que para mostrar de manera clara la brecha que existe entre el pensamiento de quienes realmente mandan en el país y los factores que - según lo planteado por el señor Wolfensohn- acechan de manera muy peligrosa a su "modelo", la situación actual de las y los trabajadores de la administración pública es sumamente ilustrativa.

\section{La situación general en el sector público}

La Carta Internacional Americana de Garantías Sociales, conocida como Carta de Bogotá, se encuentra constitucionalmente reconocida en nuestro país desde 1950. Tras ello, tanto la llamada Ley Fundamental de 1962 como la de 1983 retomaron casi textualmente las mismas disposiciones, con la idea de brindar una mayor protección a las y los trabajadores, convirtiendo a nuestro sistema en garante de sus derechos. Pese a ello y a todo lo ocu-

1. Coordinador residente del sistema de las Naciones Unidas y representante residente del Programa de las Naciones Unidas para el Desarrollo. 
rrido durante los años setenta y ochenta, en El Salvador actual no aprendemos las dolorosas lecciones y aún nos encontramos casi a diario con una serie de arbitrariedades e ilegalidades cometidas contra el sector laboral.

En ese marco, las y los empleados públicos están siendo víctimas de una serie de atropellos que poco a poco - aunque no sean tan visibles por el temor a la participación y el reclamo social- están adquiriendo niveles alarmantes. Eso sucede pese a que la lógica indica que tales personas deberían estar más protegidas por ser contratadas bajo el régimen de Ley de Salarios, e incluso por existir normativas específicas para su beneficio, como la Ley del Servicio Civil, la Ley de la Garantía de Audiencia para los Empleados Públicos no comprendidos en la Carrera Administrativa y la Ley de la Carrera Judicial. Mediante ellas se regulan sus derechos y obligaciones, y se establecen, además, los procedimientos adecuados acorde a la normativa secundaria y con respeto a nuestra Carta Magna, tanto para la imposición de sanciones a los que las violan como en los casos de supresión de plazas y destituciones. La realidad salvadoreña indica que dichas disposiciones, por lo regular, no son acatadas por las autoridades estatales.

Lo anterior, en la mayoría de los casos, obedece a situaciones bastante anormales, ya que las distintas carteras de Estado pretenden explicar estas situaciones con el argumento de que son plazas que deben suprimirse. Sin embargo, sólo a manera de ejemplo, al revisar el Presupuesto General de la Nación para 1997 y compararlo con el de 1998, se pudo observar en muchos casos que las plazas supuestamente "suprimidas" continuaron vigentes con los mismos salarios e, incluso, se crearon otras nuevas. De igual forma se han producido despidos alegando mala conducta e irresponsabilidad de parte de las y los trabajadores; eso, en la mayoría de los casos, ha sido desvirtuado mediante procesos judiciales.

La explicación para que estén sucediendo hechos de ese tipo más bien se puede encontrar al considerar el modelo económico neoliberal que actualmente está imponiendo el gobierno salvadoreño, uno de cuyos pilares resulta ser la privatización de empresas estatales dentro de las cuales se han llevado a cabo una serie de arbitrariedades con-

tra sus trabajadoras y trabajadores, vulnerando desde todo punto de vista la seguridad jurídica y la estabilidad laboral. Sin duda, esas acciones contrarían lo establecido en el artículo 37 de nuestra Constitución, según el cual al Estado le corresponde velar por la protección del trabajo, así como también procurar armonizar las relaciones entre trabajadores y patronos; ello, en nuestro país, no está sucediendo.

Es importante señalar que a pesar de que en la Ley del Servicio Civil y en la Ley de la Garantía de Audiencia para los Empleados Públicos no comprendidos en la Carrera Administrativa se determinan - de forma clara y precisa - los procedimientos adecuados para efectuar despidos o suprimir plazas, y que dentro de ellos se señala que es un deber del jefe notificar sobre una decisión de este tipo a los tribunales competentes, en la práctica no sucede así. Más bien es al mismo empleado despedido a quien - con la idea de buscar justicia- le toca iniciar las diligencias pertinentes a través de los mecanismos legales establecidos y muy pocas veces funcionales.

Además de lo anterior, es importante hacer una breve reflexión sobre la conducta del Estado salvadoreño contra el sector de las y los empleados públicos, no obstante la prohibición expresa contenida en el Convenio 98 de la Organización Internacional del Trabajo (OIT) en relación con cualquier acto de injerencia que les afecte en sus organizaciones. Dicha disposición se encuentra -en alguna medida - recogida de igual forma en nuestro Código de Trabajo vigente. Nadie puede negar que la historia laboral salvadoreña está firmemente marcada por conductas contrarias a esas regulaciones, no sólo por parte de los empleadores sino 
también del Estado mismo. Si bien es cierto que en la actualidad - por de pronto- no se han utilizado medios físicos de violencia para coartar este derecho, no por ello puede afirmarse que dichas conductas contra las y los trabajadores hayan variado en lo esencial, pues ahora se les violenta con formas más elaboradas y sofisticadas.

Por citar algo, hoy en día se les niega el derecho a la garantía de audiencia consagrado en el artículo 11 de la Constitución de la República, según el cual nadie puede ser privado de sus derechos sino después de haber sido escuchado y vencido en un juicio. Sin embargo, en los despidos que hoy se están realizando no se sigue el procedimiento establecido, mediante el cual la persona afectada puede conocer los motivos de su destitución y oponerse a ese
... las y los empleados públicos están siendo víctimas de una serie

de atropellos que poco a poco -aunque no sean tan visibles

por el temor a la participación y el reclamo socialestán adquiriendo niveles alarmantes. laboral, las políticas hacia las y los trabajadores continúan siendo confrontativas y represivas, ya que las negociaciones - a pesar de estar presentes las partes interesadas y, en algunos casos, contar con la mediación de elementos de la Asamblea Legislativa e instituciones sociales de derechos humanos- casi nunca prosperan hasta llegar a obtenerse el resultado esperado, pues no existe voluntad para ceder y aceptar errores. En esa situación, quien más pierde es el sector de las y los trabajadores, que busca en principio soluciones extralegales para garantizar la seguridad jurídica de su situación.

Tales negociaciones son necesarias e indispensables para fomentar y desarrollar logros de justicia y equidad. Por tanto, es necesaria la participación de trabajadores y empleadores - por ser ésacto presentando las pruebas de descargo a su favor. Pero, tal como se señalaba antes, los empleadores no proceden de la forma legalmente determinada y dejan sin oportunidad de defensa a las y los empleados, o hacen que sean ellas y ellos quienes tengan que buscar la manera de obtener la difícil ansiada justicia.

La falta de interés estatal por respetar los derechos laborales se refleja en la tendencia a despedir, en muchos casos, a ciertas personas por pertenecer éstas a corrientes ideológicas distintas de las del partido oficial, lo cual no es algo nuevo sino que ha sido característico de los diversos grupos políticos que han ocupado las distintas administraciones gubernamentales en nuestro país. De la misma forma podría considerarse que el Estado viola el principio de inocencia de las y los trabajadores, cuando al despedirlos los obliga a retirarse de sus puesto de trabajo y los castiga al dejarlos sin sus salarios, hasta que prueben su no culpabilidad en las acusaciones formuladas dentro de los procesos iniciados en su contra, procesos que, como antes señalábamos, en la mayoría de los casos no son iniciados por el Estado -que es a quien le corresponde hacerlo- sino por las víctimas de tales acciones.

No obstante las prohibiciones plasmadas en las leyes antes mencionadas para favorecer al sector tas las partes naturales en todo tipo de contratación- para que, en el marco de un espacio real y con bases sólidas, puedan utilizar mecanismos de conciliación. Pero también es necesario que, una vez adquiridos los compromisos, éstos sean tomados en serio y sobre todo sean cumplidos de manera pronta y oportuna, haciendo de lado cualquier tipo de diferencias ideológicas y los intereses de grupos particulares.

No podemos dejar de lado las posiciones que adoptan distintos funcionarios estatales, quienes al recibir copias de las sentencias firmes y ejecutoriadas no las acatan. Así, no se reinstala a las personas despedidas ni se reconocen salarios no devengados por causas imputables al patrono, alegando que no tienen fondos para cancelarlos y que las plazas se encuentran suprimidas. Ese tipo de argumentos a todas luces resultan ser pretextos para no obedecer las órdenes judiciales que son de obligatorio cumplimiento, y con ello tan sólo se están incrementando los niveles de impunidad y de burla a la legislación que —en la práctica - resulta ser letra muerta para los intereses de las y los trabajadores.

De igual forma es provechoso traer a cuenta los bajos salarios que las y los trabajadores perciben como producto de sus servicios prestados; salarios que no responden a las necesidades de las 
personas y sus familias, pues no se incrementan en la medida que aumenta el alza de los precios de los productos básicos y el costo de la vida en nuestro país. Los salarios para el sector laboral en El Salvador tienden a situarse en el mínimo legal, lo que - junto a otros factores- genera una elevada tasa de rotación en los empleos y lleva al trabajador a pasar por largos períodos en los cuales lo único que puede hacer es realizar labores ocasionales o permanentes en el sector informal.

La actual agudización de las crisis económica que golpea a los hogares de las y los trabajadores del sector público debería motivar al gobiemo salvadoreño a garantizar, mediante reformas a la legislación laboral, el derecho de la población al trabajo; sólo de esa manera puede privilegiarse el desarrollo de las potencialidades del ser humano y su reivindicación como principio y fin de la actividad del Estado. En este sentido, el gobierno debe garantizar la permanencia de las y los trabajadores públicos en sus actuales puestos de trabajo y el respeto a sus derechos laborales reconocidos por las leyes nacionales e internacionales. De no suceder eso, se estará provocando una mayor agudización de la inestabilidad social y, por lo tanto, poniendo en mayor riesgo la ya deteriorada "gobernabilidad" en nuestro país. Dichas reformas deben estar basadas en el respeto a la legalidad nacional y a las normas internacionales, especialmente a los convenios 87 y 98 de la OIT, cuyo cumplimiento por parte de las autoridades es obligatorio, en virtud de lo establecido en el artículo 144 de nuestra Constitución.

Dichas reformas, entonces, deben ir encaminadas a convertirse en instrumentos eficaces para propiciar la despolarización, así como para lograr la paz social y laboral en nuestro país. Por tanto, éstas deben evitar ser de contenido represivo, desconocedoras y limitativas de los derechos fundamentales de las y los trabajadores: a ello se comprometió el Estado salvadoreño el 3 de noviembre de 1993, fecha en la que asumió la responsabilidad de respetar las propuestas de la OIT, lo cual - hasta la fecha - no ha cumplido.

\section{Casos exitosos en la lucha contra la discre- cionalidad patronal}

Desde aproximadamente hace diez años se viene impulsando en nuestro territorio un esquema de ajuste estructural en el marco del llamado "neoliberlismo", que ha afectado la institucionalidad del Estado y generado severos desequilibrios en las relaciones entre las partes involucradas en su funcionamiento. En el caso particular de nuestro país, el impulso del proceso privatizador no ha respetado fundamentales principios constitucionales y, en algunos casos, ni siquiera se ha desarrollado de acuerdo con la legislación secundaria.

Decenas de miles de personas, algunas de ellas con más de quince años laborando en la administración pública, durante los últimos tres años quedaron irremediablemente sin trabajo. Con suerte hubo personas que recibieron al menos una cantidad de dinero en concepto de indemnización, como ocurrió con las que laboraban en la Administración Nacional de Telecomunicaciones (ANTEL); pero fueron numerosos los casos de aquellas que se encontraban sin prestaciones sociales y - para colmo de males- al tiempo de su retiro forzoso tenían más de treinta y cinco años de edad, lo que las ha colocado en una situación mucho más lejana e incierta de otro empleo. En ese marco, varios sindicatos fueron desarticulados so pretexto de una pretendida modernización del Estado. Muchos de los despidos y las supuestas plazas innecesarias tenían que ver con líderes sindicales y miembros activos de esas organizaciones, cuya trayectoria, desde luego, se había caracterizado por su oposición al partido oficial en las contiendas de la política partidarista.

El desorden imperante debido a la dispersión de leyes y los regímenes laborales mixtos o combinados, junto a la poca o nula experiencia en el país para exigir responsabilidad al Estado por actos que vulneran los derechos fundamentales de las personas, hacen que el problema ahora abordado sea aún mayor. La actividad de las instancias administrativas o judiciales encargadas de tutelar 
los derechos laborales dentro del sector público - cuando ésta se produce - resulta lenta, fuertemente comprometida con los titulares del Órgano Ejecutivo y, muchas de las veces, marcada por el desconocimiento sobre la materia.

Instrumentos y organismos internacionales de vigilancia y protección a los derechos de las y los trabajadores no son utilizados. Ocurre también que cuando las personas afectadas los buscan e intentan hacerlos funcionar para su beneficio, las recomendaciones emanadas desde las autoridades correspondientes - principalmente las de la Organización Intemacional de Trabajo (OIT) - han sido ignoradas por parte de quienes deberían ponerles atención y acatarlas. En definitiva, no inspiran confianza porque siempre han sido objeto de irrespeto.

Las experiencias conocidas y de alguna forma construidas por algunos gremios o grupos de trabajadores que se han presentado al Instituto de Derechos Humanos de la UCA, a través de su Oficina de Procuración de Justicia, confirman lo anterior. Por ello podemos citar, con exacto conocimiento de causa, la situación de las y los trabajadores de la Dirección General de Correos y de la Dirección General de Transporte Terrestre. Por razones de espacio y por ser sumamente ilustrativas, sólo a ellas nos referiremos en esta oportunidad aunque no son las únicas.

\subsection{El caso "Correos"}

En mayo de 1997, por razones eminentemente políticas, fue despedido un grupo de trabajadoras y trabajadores de esta dependencia del Ministerio del Interior. Las víctimas del arbitrario hecho conocieron el motivo - "pérdida de confianza"- y tuvieron que abandonar casi definitivamente su empleo, sin que se respetaran las normas del debido proceso administrativo aplicables, al menos en teoría, frente a este tipo de situaciones; normas que se encuentran contempladas en la Ley de la Garantía de Audiencia para empleados no comprendidos en otra legislación secundaria: la del Servicio Civil. En aquella época, al menos de manera temporal, se logró dar marcha atrás a esa ac- ción contraria a varios derechos fundamentales de estas personas; sin embargo, después el director de Correos movilizó el sistema al iniciar juicios sumarios para que los despidos tuvieran lugar conforme a lo establecido en las leyes.

En ese estado de cosas y conociendo su situación altamente desventajosa, las y los trabajadores solicitaron asesoría legal en el IDHUCA y ésta les fue brindada, como se hace siempre que existe la capacidad y mérito para ello: desde el principio hasta el final. Así, los juicios iniciados por la autoridad concluyeron con la obtención, en cada uno de los casos, de fallos favorables para las personas lanzadas a la calle; sucedió, pues, lo que debía suceder en cualquier país donde se respeta la legalidad y la gente puede acudir confiada a las instituciones oficiales para hacer valer sus derechos. En otro sitio éste sería un resultado lógico, pues no existía motivo real para efectuar los despidos; pero en nuestro país sí que es un hecho extraordinario lograr que una autoridad judicial le ordene a la Dirección General de Correos la reinstalación y pago de los salarios caídos a cualquier persona cuando, en su separación del cargo ocupado, se detectan instrucciones provenientes de algún sitio más alto dentro del aparato estatal, las cuales evidentemente tienen que ver con razones de índole política.

Y es que, en la mayoría de los casos, el verdadero móvil del despido no fue ni la "privatización" del Estado ni la "ineficiencia" de cada una de estas personas, como intentó hacer creer la cuestionada dependencia cuando su funcionario máximo inició los juicios; más bien, la razón última del drama sufrido por estas personas y sus familias fue de otra naturaleza: una lamentable reacción ante la simpatía de estos trabajadores por otros partidos políticos distintos de la Alianza Republicana Nacionalista (ARENA).

Las mencionadas resoluciones judiciales fueron pronunciadas entre diciembre de 1997 y julio de 1998; pero, como sucede en ésta y otras materias dentro de nuestro El Salvador de antes y después de la guerra, la Dirección General de Correos no le dio el fiel e inmediato cumplimiento al con- 
tenido de las mismas. Luego de varios intentos inútiles para lograr entrevistas con funcionarios de dicha dependencia, sobre todo en su departamento jurídico, el panorama era desalentador: nada se lograba en favor de las personas que, sin trabajo, no encontraban cómo aliviar las necesidades más elementales de sus familias.

Había que echar mano de una buena dosis de audacia y apuntar más arriba: en marzo del presente año fueron presentadas sendas notas al titular de la cartera del Interior, firmadas por las víctimas que solicitaban el exacto acatamiento de lo establecido judicialmente. De las comunicaciones del 8 y 26 de ese mes se obtuvo un resultado positivo, o al menos eso pareció: las y los trabajadores despedidos fueron convocados a la sede central de la Dirección General de Correos donde el personal de la Oficina de Recursos Humanos, de manera verbal, les ofreció disculpas por el atraso considerable en el cumplimiento de las sentencias y les informó que podían presentarse a laborar a partir del 12 de abril; mientras llegaba ese día, los funcionarios se comprometieron a buscar fondos para cancelar los salarios adeudados, aunque mencionaron que la situación indefinida por la que atravesaba en ese momento la aprobación del Presupuesto General de la Nación en el seno legislativo, podía afectar negativamente sus intereses.

Frente al proceder antes referido, las personas afectadas se sintieron satisfechas, pero - por las experiencias negativas que habían vivido- advirtieron que esperarían un tiempo prudencial para ver cumplido en su totalidad lo ordenado por la autoridad judičial competente, incluyendo lo relacionado con la cancelación de los salarios adeudados a las y los trabajadores por todo el tiempo que no habían laborado, en razón del proceso que en su contra promovió en el tribunal el Director General de Correos.

Pese a que lograron sus objetivos, el final de esta historia no fue del todo feliz por dos aspectos que deben ser resaltados. Uno referido al tiempo que debían durar los procesos, que por ser sumarios suponían un período no mayor de treinta días; sin embargo, en estos casos los más "breves" superaron los seis meses. El segundo elemento por considerar: entre la fecha en la que el Órgano Judicial dio por ejecutoriadas las sentencias favorables a las y los trabajadores hasta el cumplimiento de lo ordenado en ellas, transcurrieron no menos de seis meses; sin duda, ése no es el tiempo que se debe esperar legalmente para acatar una orden de ese tipo ni el que puede soportar una familia sin tener un salario básico para vivir.

Cabe hacer notar que no se procedió a dicho cumplimiento sino hasta que se mencionó, en un escrito dirigido a la Dirección General de Correos, que se promovería un antejuicio contra el Ministro del Interior por el delito de desacato a lo ordenado judicialmente; vistos los acontecimientos posteriores, es válido imaginar que —de cara a las elecciones de marzo de 1999 - había que hacer algo para evitar las denuncias a un nivel más público y de consecuencias mucho más caras.

\subsection{El caso de las y los "despachadores"}

Similar a la anterior nos encontramos con la situación de otro grupo de personas despedidas por la Dirección General de Transporte Terrestre. Ya se hizo referencia a lo desordenado de la legislación nacional en materia administrativa; pues bien, la regulación existente para las y los delegados de transporte -comúnmente conocidos como "despachadores de buses"- es un claro ejemplo de ello. La naturaleza laboral de estas personas surge de un nombramiento realizado por la mencionada dependencia oficial, para realizar tareas de supervisión y control de las unidades de transporte colectivo. No obstante ser nombrados por un ente estatal, los salarios que devengan - debido a la "costumbre" - son cubiertos por los empresarios 
del sector; es decir, por los dueños de los vehículos automotores a quienes el Estado - vía concesión- ha delegado la satisfacción de tan vital servicio público para la población.

Como se deduce de lo relatado en el párrafo precedente, la que nos ocupa resulta ser una combinación entre extraña y desventajosa para las y los delegados de transporte, puesto que su régimen laboral no contempla seguro, pensión o cualquier otra prestación laboral, salvo la que por sus propios medios puedan obtener.

En ese marco, a partir del último semestre de 1996 tuvieron lugar despidos arbitrarios de estas personas - sin consulta y sin razones para ello- por iniciativa de los empresarios, que creyeron tener el derecho de hacerlo por el hecho de pagarles los salarios. Las víctimas, imposibilitados para continuar desarrollando su labor y ganar así el sustento para sus familias, solicitaron la intervención de la Dirección General de Transporte Terrestre; ésta, no obstante haber enviado circulares a algunas líneas de buses prohibiendo la realización de más despidos, no intervino en aquellos casos de las y los dele-

gados que ya habían sufrido el atropello. En poco tiempo llegaron a sumar más de doscientas personaş afectadas sin que la Dirección asumiera, de manera enérgica y seria, cartas en el asunto.

De esa forma, la Asociación Mutualista de Delegados de Transporte se presentó al IDHUCA para solicitar asesoría legal y mediación; fue así que se elaboró una petición formal a la dependencia estatal involucrada para buscar, de su parte, una acción más decidida y decisiva en favor de las y los "despachadores" despedidos, en aras de reinstalarlos en sus puestos y que obtuvieran el pago de los salarios. Transcurrieron dos meses sin que se obtuviera respuesta alguna a dicha petición, período en el cual — según el ordenamiento vigente en materia administrativa - se entiende configurado el llamado "silencio administrativo" y con ello la denegatoria presunta a la petición realizada, abriéndose entonces la oportunidad de promover acción ante la Sala de lo Contencioso Administrativo de la Corte Suprema de Justicia.
En mayo de 1997 se promovió dicha acción argumentando, entre otras cosas, la omisión de la Dirección General de Transporte Terrestre y la situación de indefensión en la que se encontraban las y los delegados, no obstante existir un reglamento dentro del cual se contempla cuándo y cómo proceder para y ante los despidos. El juicio siguió su curso aunque a un ritmo bastante lento; se aportó prueba y se desvirtuaron en su oportunidad las superficiales excusas formuladas por la autoridad demandada hasta que finalmente, en mayo de 1999 -dos años después de presentada la demanda-, la Sala de lo Contencioso Administrativo pronunció sentencia declarando ilegal el acto, ordenando el pago de costas procesales y resolviendo positivamente las peticiones que le fueran formuladas.

En una de sus partes, la citada resolución afirma textualmente lo siguiente:

El funcionario demandado, al tener conocimiento de la situación en la que se encontraban los delegados de Transporte y en razón de las normas reglamentarias mencionadas, estaba obligado a intervenir por dos fuertes motivos: el primero por no estar facultados los empresarios de autobuses para la imposición de sanciones y el segundo por ser competencia de la Dirección General de Transporte Terrestre garantizar la estabilidad de los delegados.

De lo anterior deriva la ilegalidad del acto denegatorio presunto de petición formulada al funcionario demandado, de gestionar con los empresarios de autobuses responsables de las destituciones y despidos el pago de salarios a los delegados afectados, así como también la falta de adopción de medidas preventivas a fin de que hechos como los denunciados no se repitan en el futuro.

Así las cosas, ya fue superado el plazo de treinta días que concede la ley para que la autoridad demandada cumpla con lo dispuesto por la Sala de lo Contencioso Administrativo. Sin embargo, al momento de escribir estas líneas aún no se han restablecido los derechos violados a las $y$ los trabajadores despedidos injustamente.

En forma paralela a la promoción del juicio contencioso, en la Asamblea Legislativa -ante la $\mathrm{Co}-$ 
misión de Obras Públicas y, por algún tiempo, ante la Comisión de Trabajo- otra lucha no menos importante ha tenido lugar en defensa de la fuente de trabajo. Es el caso que debido a las difíciles negociaciones y los cada vez mayores descontentos entre empresarios y delegados, la posibilidad de suprimir las plazas comenzó a tener eco entre las y los diputados integrantes de estas dos comisiones parlamentarias; ello obligó a elaborar más de una propuesta para indemnizar a las y los "despachadores" según su tiempo de servicio.

El principal obstáculo que se ha tenido que enfrentar para definir y aceptar una propuesta de este tipo, es el relacionado con la fuente de donde provendrían los fondos para tales indemnizaciones. Así, se maneja que éstas bien podrían derivarse de descuentos del subsidio al combustible ("diesel") y entonces correr el pago por cuenta de los empresarios; otra posibilidad se vislumbra con la creación de un pago por derecho de explotación de línea para los empresarios, para ser cobrado por la Dirección General de Transporte Terrestre. En cualquiera de los dos casos, son los empresarios y no el Estado el que pagaría; eso, desde nuestro punto de vista, no es del todo conveniente ni mucho menos admisible, dado que éste último estaría evadiendo su responsabilidad y los empresarios tendrían pretextos de sobra para oponerse a tales cobros o deducciones. En definitiva, quienes siempre resultarían afectadas serían las personas más vulnerables y sus familias.

\section{Conclusión}

En los dos casos antes resumidos destaca la función determinante que ha desempeñado el Órgano Judicial. En el primero de ellos se logró establecer, a través de un juicio sumario, que no se configuraban las causales invocadas por el Director General de Correos para despedir a sus trabaja- dores; en el segundo, se estableció la obligación para el funcionario demandado de pronunciarse y ordenar la situación ante la actitud abusiva de empresarios de transporte colectivo, cuando éstos procedieron al despido de las y los delegados. $Y$ es que en el juego de los llamados "pesos y contrapesos" dentro de una sociedad, es necesario que así se funcione ya que en él descansa precisamente todo Estado que se precie de estar fundado en el Derecho y ser respetuoso de la legalidad; de lo contrario, cualquier funcionario podrá disponer cualquier cosa y nadie podrá intervenir para remediarlo.

Si bien no ha sido ese funcionamiento correcto el denominador común en el comportamiento que la población salvadoreña ha observado en la mayor parte de los casos, vale la pena destacar lo ocurrido en estos dos - triunfos parciales en ambos, pero triunfos a fin de cuentas, sobre todo cuando en ese juego el rol más importante le ha correspondido a grupos de personas sencillas, "comunes y corrientes", que se decidieron a no seguir siendo víctimas del sistema de injusticia e impunidad para pasar a la acción de hacer valer sus derechos.

Y el valor de estos esfuerzos es mayor cuando, a diferencia de otros países, en el área centroamericana y la región latinoamericana, en El Salvador no contamos en la actualidad con una herramienta importante que nos permita hacer valer los derechos económicos, sociales y culturales en general, así como los derechos al trabajo y a la protección legal cuando éste último es violentado: la tutela de la Procuraduría para la Defensa de los Derechos Humanos, lastimosamente entregada a los intereses particulares de ciertos grupúsculos políticos. En este punto, cabe traer a cuenta lo siguiente: "La institución del Ombudsman y el papel que vienen jugando los defensores del pueblo en la región, son sin duda un complemento fuerte de las estrategias de exigibilidad en la región"2.

2. Centro de Asesoría Legal del Perú (CEDAL), "Desafíos para la exigibilidad de los derechos económicos, sociales y culturales", Plataforma.Sudamericana de Derechos, Democracia y Desarrollo, julio, 1999, p. 19. 


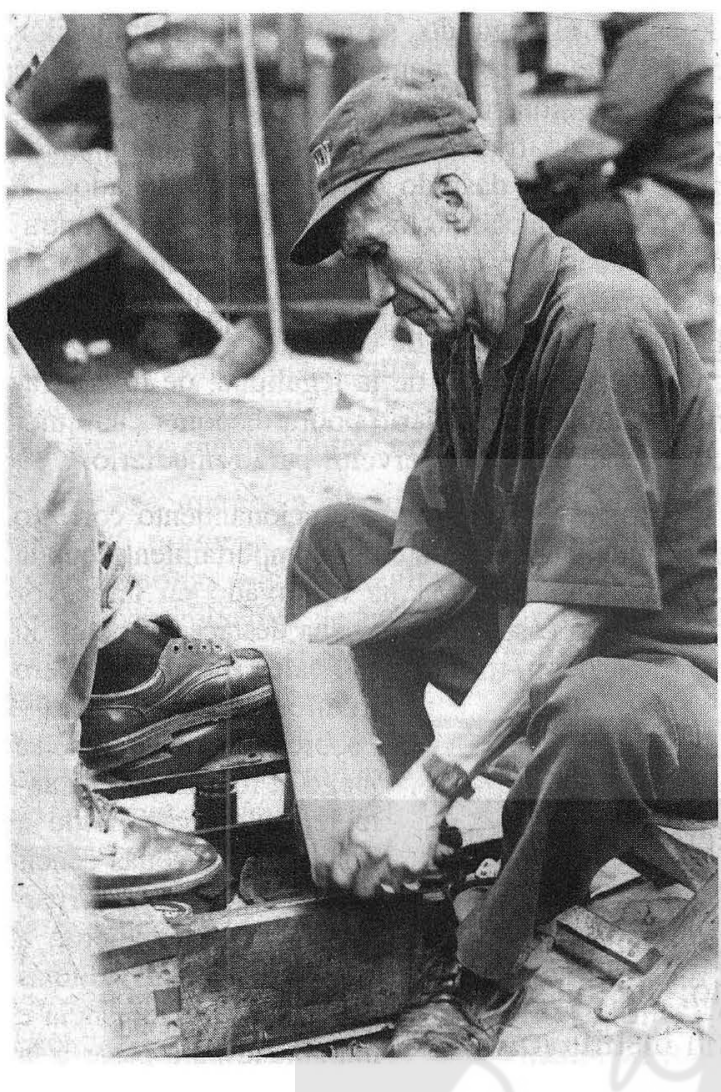

No obstante lo anterior, otro paso que se debe dar para avanzar más y completar los éxitos es el cumplimiento total y efectivo de lo ordenado por el Órgano Judicial. Para que el Ministerio del Interior acatara lo resuelto por distintos tribunales en el país a favor de empleados y empleadas despedidas por la Dirección General de Correos, se necesitó hasta de la presión internacional; finalmente se consiguió. En cuanto al segundo caso, será necesario iniciar nuevas acciones legales para alcanzar un resultado enteramente positivo, pese a que mientras llega ese momento, el sufrimiento para muchas familias salvadoreñas continuará.

De cualquier manera, ambos casos han de servir como ejemplo al resto de trabajadores y trabajadoras, así como a funcionarios estatales, incluidos aquellos responsables de que en El Salvador la mayoría de la población viva en una situación realmente angustiante; de que todas y todos nos sensibilizemos ante lo peligros del panorama y participemos conjuntamente en la búsqueda de una pronta justicia en lo social y lo legal.

Se trata pues —afirma Alejandro Teitelbaunde comenzar a despertar la alarma social frente a esta clase de criminalidad. Se refiere a la violación de los derechos económicos, sociales y culturales, dado que la opinión pública está condicionada de manera tal que reacciona contra el que roba una cartera en la calle o comete un homicidio, pero que considera que todo está en el orden normal de las cosas, o que corresponde a las leyes del mercado, el saqueo sistemático de naciones enteras, y la condena al hambre, a la enfermedad y a la muerte de millones de seres humanos ${ }^{3}$.

Cuando instrumentos internacionales de protección de los derechos humanos se refieren al "deber de garantía" por parte de los Estados, están hablando precisamente de esto: que puedan ofrecer a la población instituciones ante las cuales se pueda - con entera confianza - reclamar y obtener la tutela de los derechos fundamentales; para el caso que nos ocupa, el derecho al trabajo. Sin lugar a dudas, es mediante soluciones como éstas que se puede alcanzar el respeto de las leyes y se hace valer la preeminencia de la dignidad de todas las personas dentro del marco de nuestra Constitución, por encima de cualquier capricho político partidista o determinados intereses económicos. Veremos cuál es la actuación del recién estrenado gobiemo en materia laboral y su comportamiento ante las decisiones judiciales obtenidas con el esfuerzo de la población en favor de sus causas más sentidas.

En ese marco y a la espera de lo que pueda ocurrir con la nueva administración del Ejecutivo, consideramos que para finalizar es necesario dejar pendiente una reflexión más profunda sobre lo siguiente:

El movimiento por la integralidad de los derechos humanos va contracorriente del pensamiento único que nos quiere imponer el neoliberalismo. Este pen-

3. Alejandro Teitelbaun, "Derecho al desarrollo y los derechos económicos, sociales y culturales: criminalización de su violación", Asociación Americana de Juristas, p. 33. 
samiento consiste en ver la vida y organizarla a partir del mercado. Va contracorriente también del impacto que la mudialización de la economía, las políticas de ajuste y la reforma del Estado tienen sobre el sentido común de la gente, que ve reducida su condición de ciudadana a la de clientes individuales, propiciando así la abdicación de derechos frente al Estado y, sobre todo, frente al mercado ${ }^{4}$.

4. Centro de Asesoría Legal del Perú (CEDAL), op. cit., p. 21. 